\title{
Intelligent Vehicle Speed Controlling and Pothole Detection System
}

\author{
Aditya Anand ${ }^{l, *}$, Rushiraj Gawande ${ }^{l}$, Prathamesh Jadhav ${ }^{l}$, Rima Shahapurkar ${ }^{l}$, Anjali Devi ${ }^{l}$, and NikhilKumar ${ }^{l}$ \\ ${ }^{\prime}$ JSMP'S Jayawantrao Sawant College of Engineering, Pune, Maharashtra, India.
}

\begin{abstract}
Speed is the single largest killer on India's roads. The higher the speed, the greater the impact and the more the chances of grievous injury and death. This is why speed management is something which needs to be seriously considered. Here is an approach to build a system which reduces the number of accidents due to driver's negligence of over speeding. We are proposing a Dynamic Speed Limiter with the help of machine learning algorithm which will help in reducing the accidents caused due to over speeding and rash driving of vehicles on road. The proposed system set the maximum speed of vehicle with the help of sign board available on the roads which define the safe driving speed of vehicle for that area or road. Also to solve the potholes we are using ML algorithm and mobile phone accelerometer to detect the potholes, accelerometer vibrations are set. After detecting the vibrations, the location (i.e. longitude and latitude) is marked on the GPS, commuters will get information about potholes.
\end{abstract}

Keywords- Speed Limiter, Camera, Image Processing, Sign-Board, CNN, SVM, OpenCV, MCU (Raspberry $\mathrm{Pi}$ ).

\section{Introduction}

According to the World health organization, around the world approximately 1.35 million die every year due to road accidents. Injuries caused on the road are one of the sixth leading causes of death in India with a higher percentage of hospitalization, loss of lives, disabilities and socio- economic losses to the mankind. We have come up with the solutions of two of the major causes of accidents.

Firstly, speeding, speeding endangers everyone on the road. According to Central Ministry of Road Transport and Highway India[1], in 2017 speeding on road was reason for death of 9717 peoples accounting for more than a quarter $(26 \%)$ of all the traffic caused fatalities. Speeding endangers not only the life of the speeder but also all the commuters around them. To solve this cause, we are designing and implementing a dynamic speed limiter through image processing technique. As, the speed-limit sign board recognition system has two separate tasks: first is the detection stage and second is the recognition stage. The detection stage is responsible for detecting the sign board from the image, and in the recognition stage the values specified in the sign board will be identified. In the recognition stage, template matching or learning- based classification techniques are usually used[2,3]. For learning- based classification, Artificial Neural Networks and Support Vector Machines (SVMs) have been widely investigated . Recently, Convolutional Neural Network (CNN) has been used to recognize traffic signs and has high accuracy[4], however, huge computation resource is usually required either in training or test phases. In this paper, we introduce an automatic detection and recognition system of speed- limit sign board that can handle different conditions of lighting and blurriness in images[5,6]. The system uses a detection method based on MSER detection and recognizes speed-limit signs with Histogram of Oriented Gradient (HOG) features by a SVM classifier. Further this limit is provided input to

*Corresponding author: anandaditya59@gmail.com 
the speed limiter through MCU. The speed limiter then sets the maximum speed of the vehicle which restricts the vehicle to over speed.

Second one is the pothole; potholes are also one of the major reasons of accidents[1]. According to the data shared by states to Centre Uttar Pradesh, India logged most such deaths at 987. In the year 2017, 4250 people died nearly on the roads which were under construction. To solve this cause, we are using ML algorithm and mobile phone accelerometer to detect the potholes, accelerometer vibrations are set. When a user passes on the potholes for the first time,

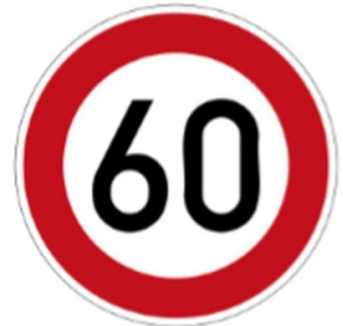

Fig. 1. A typical speed limit sign board
Accelerometer in mobile phones detects the pressure of potholes based on the vibration. After detecting the vibrations, the location (i.e. longitude and latitude) is marked on the GPS, commuters will get information about potholes via updated Maps and also the location will be sent to the corporation to fix the potholes.

\section{Literature Survey}

According to the traditional Systems and prior research, the methodologies and technologies used to control the vehicle speed using the sign board where the speed limit is mentioned but we can still exceed that limit and move with a higher speed. This is the major reason for fatal accidents and loss of lives.

Following we have mentioned some important researches which have some advantages and limitations which are been surveyed.

Table. 1. Literature Survey of some papers

\begin{tabular}{|c|c|c|c|c|c|}
\hline $\begin{array}{l}\text { Sr. } \\
\text { no }\end{array}$ & Title of Paper & $\begin{array}{l}\text { Author } \\
\text { Name }\end{array}$ & Advantages & Techniques Used & Drawbacks \\
\hline 1. & $\begin{array}{l}\text { Automatic } \\
\text { Recognition of } \\
\text { Speed Limits on } \\
\text { Speed-Limit } \\
\text { Signs by Using } \\
\text { Machine } \\
\text { Learning }\end{array}$ & $\begin{array}{l}\text { Shigeharu } \\
\text { Miyata }\end{array}$ & $\begin{array}{l}\text { This study describes } \\
\text { a method for using a } \\
\text { camera to } \\
\text { automatically } \\
\text { recognize the speed } \\
\text { limits on speed-limit } \\
\text { signs }\end{array}$ & $\begin{array}{l}\text { Machine Learning with } \\
\text { local binary pattern } \\
\text { recognition, Image } \\
\text { Processing with HSV, } \\
\text { Neural Network }\end{array}$ & $\begin{array}{l}\text { number extraction was } \\
\text { not successful due to } \\
\text { signs with faded colors, } \\
\text { signs that were backlit, } \\
\text { or signs that were } \\
\text { partially hidden by trees } \\
\text { or other objects }\end{array}$ \\
\hline 2. & $\begin{array}{l}\text { Wireless Speed } \\
\text { Controlling } \\
\text { Module For Two } \\
\text { Wheelers }\end{array}$ & $\begin{array}{l}\text { 1. P.R. } \\
\text { Sonawane } \\
\text { 2. Vinayak } \\
\text { Kaviskar } \\
\text { 3. Abhinav } \\
\text { Kumar } \\
\text { 4. Debabrata } \\
\text { Karmakar }\end{array}$ & $\begin{array}{l}\text { Intimate the driver } \\
\text { about the zones and } \\
\text { to automatically } \\
\text { maintain the speed is } \\
\text { accomplished by } \\
\text { means RF } \\
\text { technology. }\end{array}$ & $\begin{array}{l}\text { micro controller along } \\
\text { with a RF transmitter, } \\
\text { speed sensor, RF } \\
\text { receiver, Servo motor }\end{array}$ & $\begin{array}{l}\text { Implemented system } \\
\text { works only for two } \\
\text { wheelers }\end{array}$ \\
\hline 3. & $\begin{array}{lr}\text { Real Time } \\
\text { Pothole Detection } \\
\text { using Android } \\
\text { Smartphones with } \\
\text { Accelerometers }\end{array}$ & $\begin{array}{l}\text { 1. Artis Mednis } \\
\text { 2. Girts } \\
\text { Strazdins } \\
\text { 3. Reinholds } \\
\text { Zviedris } \\
\text { 4. Georgijs } \\
\text { Kanonirs }\end{array}$ & $\begin{array}{l}\text { The paper is } \\
\text { describing a mobile } \\
\text { sensing system for } \\
\text { road irregularity } \\
\text { detection using } \\
\text { Android OS based } \\
\text { smart-phones. }\end{array}$ & $\begin{array}{l}\text { Android OS based } \\
\text { smart-phone, } \\
\text { accelerometer sensors }\end{array}$ & $\begin{array}{l}\text { System only detects the } \\
\text { potholes without alerting } \\
\text { the users. }\end{array}$ \\
\hline 4. & $\begin{array}{l}\text { RoADS: A Road } \\
\text { Pavement } \\
\text { Monitoring } \\
\text { System for } \\
\text { Anomaly } \\
\text { Detection Using } \\
\text { Smart Phones }\end{array}$ & $\begin{array}{l}\text { 1.Fatjon Seraj } \\
\text { 2.Berend Jan } \\
\text { van der Zwaag } \\
\text { 3. Arta Dilo } \\
\text { 4. Tamara } \\
\text { Luarasi }\end{array}$ & $\begin{array}{l}\text { In this paper we } \\
\text { proposed a system } \\
\text { that detects road } \\
\text { surface anomalies } \\
\text { using mobile phones } \\
\text { equipped with inertial } \\
\text { sensors: }\end{array}$ & $\begin{array}{l}\text { Smartphone orientation } \\
\text { inside the vehicle, } \\
\text { accelerometer, anomaly } \\
\text { detection supervised } \\
\text { machine learning } \\
\text { techniques }\end{array}$ & $\begin{array}{l}\text { time consuming process } \\
\text { of manual labeling }\end{array}$ \\
\hline
\end{tabular}




\begin{tabular}{|c|c|c|c|c|c|}
\hline & & & $\begin{array}{l}\text { accelerometers and } \\
\text { gyroscopes. }\end{array}$ & & \\
\hline 5. & $\begin{array}{l}\text { Vehicle Collision } \\
\text { Avoidance with } \\
\text { Dynamic Speed } \\
\text { Governor }\end{array}$ & $\begin{array}{l}\text { 1. Kashyap A } \\
\text { R } \\
\text { 2. Mohankrish } \\
\text { na K }\end{array}$ & $\begin{array}{l}\text { The proposed system } \\
\text { is based on } \\
\text { microcontroller for } \\
\text { collecting data related } \\
\text { to speed and } \\
\text { transmitting it } \\
\text { through a transceiver } \\
\text { to a base station that } \\
\text { analyzes the } \\
\text { transmitted data and } \\
\text { takes decisions } \\
\text { related to speedlimit } \\
\text {. }\end{array}$ & $\begin{array}{l}\text { Microcontroller, } \\
\text { Software: MPLAB } \\
\text { IDE, CAD Software: } \\
\text { EAGLE, Ultrasonic } \\
\text { sensors }\end{array}$ & $\begin{array}{l}\text { Traces are placed } \\
\text { manually as done in the } \\
\text { traditional method where } \\
\text { you change the path of } \\
\text { the trace every time you } \\
\text { click the mouse. }\end{array}$ \\
\hline
\end{tabular}

\section{Research Elaboration}

\subsection{System description:}

We have come up with the solutions of two of the major causes of accidents. Firstly, speeding, speeding endangers everyone on the road. According to Central Ministry of Road Transport and Highway, in 2017 speeding on road was reason for death of 9717 peoples accounting for more than a quarter $(26 \%)$ of all the traffic caused fatalities. Speeding endangers not only the life of the speeder but also all the commuters around them.

To solve this cause, we are designing and implementing a dynamic speed limiter through image processing technique. The camera installed in front of the vehicle captures real time images of the speed limit sign board and then MCU receives the images as input for image processing. With the help of image processing detection and recognition algorithm from the captured image we detect the speed limit of that particular area. Further this limit is provided input to the speed limiter through MCU. The speed limiter[7] then sets the maximum speed of the vehicle which restricts the vehicle to over speed.

The flowchart in Figure 2 shows the complete process of speed controlling using image processing the speed limit signboard.

Second one is the pothole; potholes are also one of the major reasons of accidents. According to the data shared by states to Centre Uttar Pradesh logged most such deaths at 987 . In the year 2017,4250 people died nearly on the roads which were under construction.

To solve this cause, we are using mobile phone accelerometer to detect the potholes, accelerometer vibrations are set.

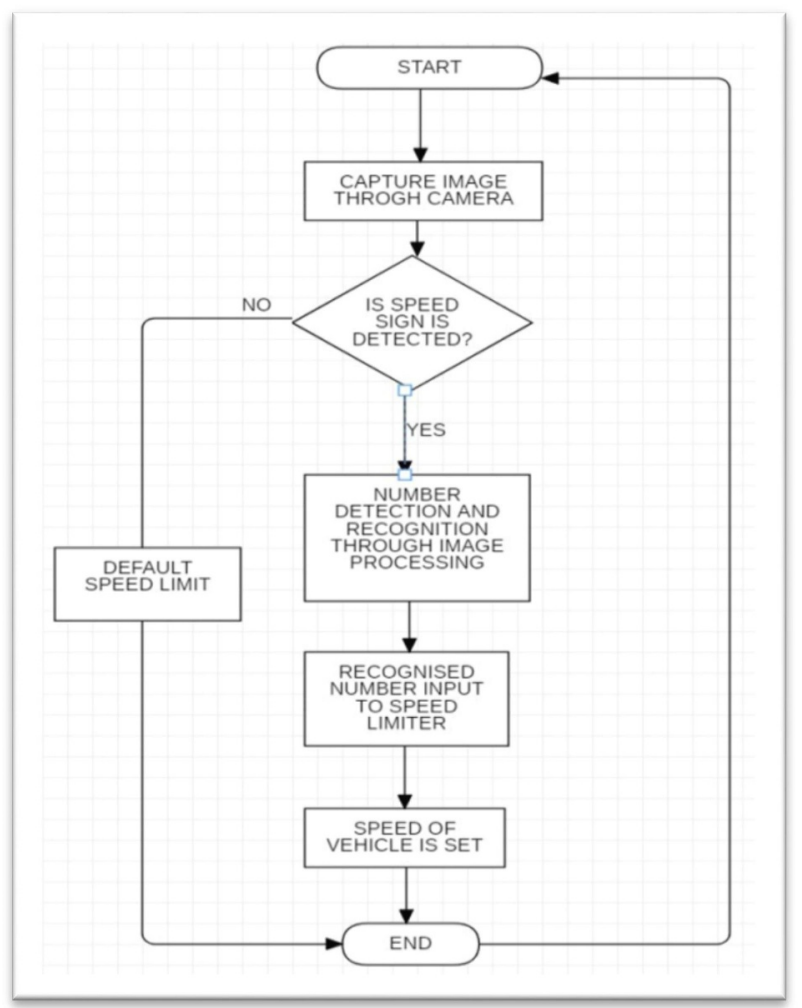

Fig. 2. Flowchart of Speed Control System

When a user passes on the potholes for the first time, Accelerometer in mobile phones detects the pressure of potholes based on the vibration. After detecting the vibrations, the location (i.e. longitude and latitude) is marked on the GPS, commuters will get information about potholes via updated Maps and also the location will be sent to the corporation to fix the potholes. The flowchart in the figure 3 shows the complete process of pothole detection using mobile accelerometer[8,9] and GPS to mark location of pothole on the Map. 


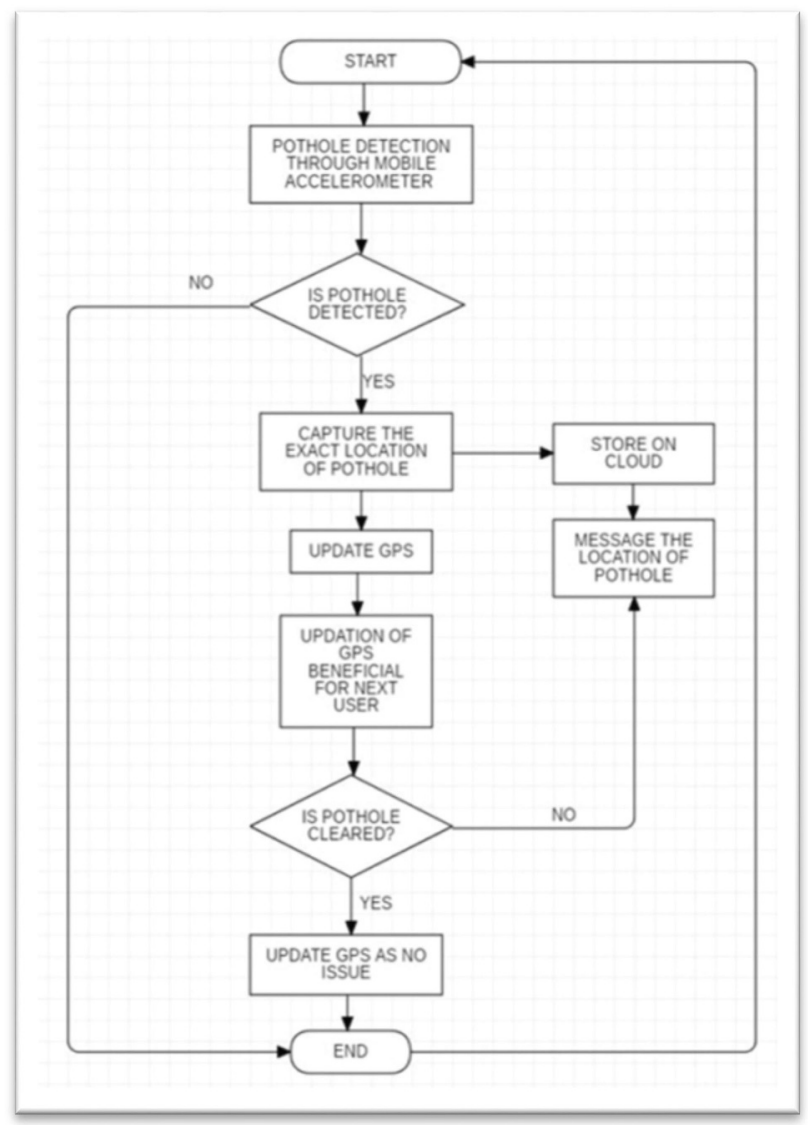

Fig. 3. Flowchart of Pothole Detection System

\subsection{System Architecture:}

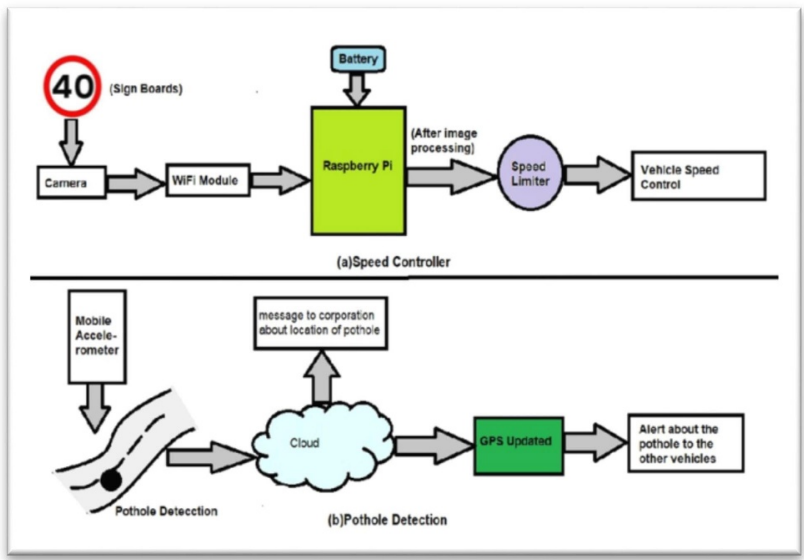

Fig. 4. Proposed Architecture

In the proposed speed controlling system the speed-limit sign board detection and recognition system works in three different stages: first preprocessing of the image, second is detection of the sign board, and third is the recognition of speed limit in the sign board. The first step, in the preprocessing stage is responsible for enhancing the input image taken from the live video so that the speed-limit sign board in real time can be more obvious. The second step, the detection stage, uses MSER detection to find speed-limit sign candidate regions. Finally, the last step, in the recognition stage is responsible for extracting the HOG features from the candidate regions and feeds it to a SVM and the class of a speed-limit sign will be classified.

Before detection, the input image needs to be processed for the detection stage to work properly and efficiently. Since the input to the MSER computation requires grayscale image, we need to convert the input RGB image to a grayscale one. Also, the speed-limit signs are designed to have bright red colors, so we can take advantage of this feature and emphasize the pixels that have dominant red channel values. Therefore, we adapt the red color enhancement approach. For every pixel $\mathrm{x}$ $=\left[\mathrm{x}_{\mathrm{R}}, \mathrm{x}_{\mathrm{G}}, \mathrm{x}_{\mathrm{B}}\right]$ in the sign board image, where $\mathrm{x}_{\mathrm{R}}, \mathrm{x}_{\mathrm{G}}$, and $x_{B}$ are the red channel, green channel, and blue channel of the image, in the image the red color enhancement is provided by

$f_{R}(x)=\max \left(0, \frac{\min \left(x_{R}-x_{G}, x_{R}-x_{B}\right)}{x_{R}+x_{G}+x_{B}}\right)$

And the final grayscale image can be obtained by

$\operatorname{Red}(x)=\left\{\begin{array}{c}f_{R}(x), x_{R} \geq x_{G} \text { and } x_{R} \geq x_{B} \\ \text { and } x_{G} /\left(x_{R}-x_{G}\right) \leq T_{R} \\ 0, \text { otherwise }\end{array}\right.$

Where $T_{R}$ is a parameter that obtained from experiment results. The grayscale image $\operatorname{Red}(\mathrm{x})$ obtained from this way has the advantage that the outer circle of sign board in red color signs becomes more apparent.

In the detection part, the system will detect MSERs and find potential speed-limit sign regions among them. The main advantage of this approach is that the detection of MSERs is robust under different environmental conditions, such as lighting and weather of the scene or the complexity of the background. MSERs are regions in an image that maintain their shapes when the image is thresholded at several levels. The detection of MSERs is performed on a grayscale image that comes from the result of the preprocessing stage.

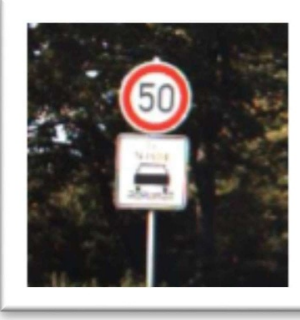

(i)

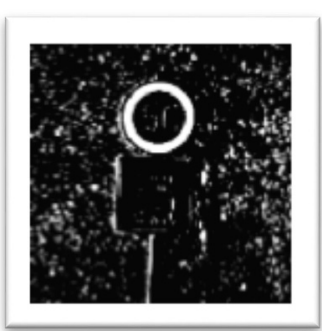

(ii) 


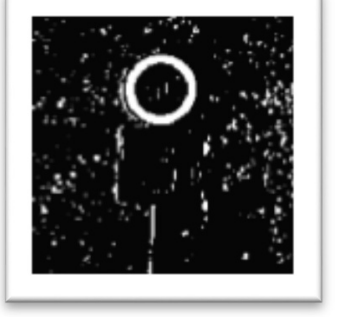

(iii)

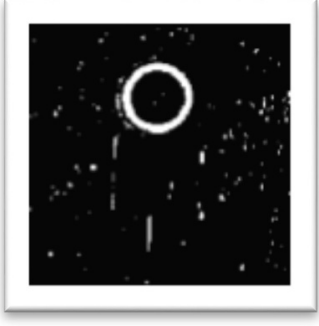

(iv)
Fig. 5. The speed-limit sign maintains its shape under different thresholds.

(i.) Original image. (ii.) The preprocessed image. (iii.) Threshold $=150$. (iv.) $T$ Threshold $=$ 250.

The recognition stage is responsible for verifying a candidate region as a speed-limit sign board. If the candidate region is actually a speed-limit sign board then, the speed-limit values present on the sign board will be determined. Otherwise, the candidate region verified by recognition stage will be discarded. In the recognition stage, the HOG features of the sign board will be extracted from the candidate region. Since speed-limit signs have strong appearance-circle shapes and high-contrast edges, HOG features are very suitable to capture these characteristics. HOG feature is computed for each candidate region and a vector will be generated. For speed and simplicity, SVM is used as a tool for the recognition stage.

After detection of the speed we set the that speed limit to the vehicle by changing the limit of speed limiter by providing it the limit by using raspberry pi. Thus, the vehicle maximum speed is set automatically by using the speed limit sign board and speed limiter.

In the proposed pothole detection system using mobile phone accelerometer to detect the potholes, accelerometer vibrations are set. When a user passes on the potholes for the first time, Accelerometer in mobile phones detects the pressure of potholes based on the vibration sensed by the mobile phone and recorded by the change in coordinates of the accelerometer. After detecting the vibrations, the location (i.e. longitude and latitude) is marked on the map by fetching the location by using mobile phone GPS, then after commuters will get information about potholes via updated Maps and also the location of the pothole will be sent to the corporation by GSM service of mobile phone to fix the potholes.

\section{Conclusion}

This paper proposes a model for the Intelligent Speed Controlling and Real time Pothole Detection and monitoring system, after detection of signboard the vehicle maximum speed will be set by using speed limiter so as to limit the vehicle maximum speed to the speed limit decided for that road and a mobile phone will be used to detect the pothole and alert the users and concerned authorities about the location of pothole. Thus, proposed system ensures the safety of user in terms of controlling the over speeding, pothole notification on map and suggesting alternative path, that he drives in an area and safety to all of the people on road around them.

\section{References}

[1]. K. K. Sandhu, IndiaToday, Over 9300 deaths, 25000 injured in 3 years due to potholes, (2018).

[2]. A. D. Lattner, A. Miene, and O. Herzog, Springer, A Combination of Machine Learning and Image Processing Technologies for the Classification of Image Regions, Adaptive Multimedia Retrieval pp 185-199, (2003)

[3]. E. Forson, Towards Data Science, Recognising Traffic Signs With 98\% Accuracy Using Deep Learning, (2017).

[4].S. Doshi, Towards Data Science, Traffic Sign Detection using Convolutional Neural Network, (2019)

[5]. R. Biswas, H. Fleyeh, M. Mostakim, IEEE, Detection And Classification Of Speed Limit Traffic Signs, 10.1109/WCCAIS.2014.6916605, ( 2014)

[6]. A. A. Dalve, S. S. Shiravale, International Journal of Computer Applications, Real Time Traffic Signboard Detection and Recognition from Street Level Imagery for Smart Vehicle, Volume 135 - No.1, (2016)

[7]. R. J. Hanowski, G. Berrgoffen, J. S. Hickman, F. Guo, ResearchGate, Research on the Safety Impacts of Speed Limiter Device Installations on Commercial Motor Vehicles: Phase II, FMCSA-RRR-12-006, (2012).

[8]. H. Song, K. Baek, Y. Byun, ResearchGate, Pothole Detection using Machine Learning, 10.14257/astl.2018.150.35, (2018).

[9]. A. Mendis, G. Strazdins, R. Zviedris, G. Kanonirs, IEEE, Real time pothole detection using Android smartphones with accelerometers,

10.1109/DCOSS.2011.5982206, (2011) 